\title{
Investigating the relation between upper extremity function and trunk control, balance and functional mobility in individuals with stroke
}

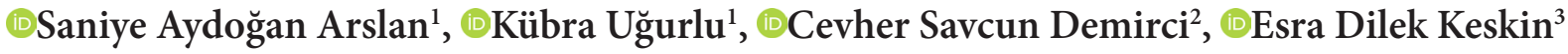 \\ ${ }^{1}$ Kırıkkale University Faculty of Health Sciences, Department of Physiotherapy and Rehabilitation, Kırıkkale, Turkey \\ ${ }^{2}$ Balıkesir University Faculty of Health Sciences, Department of Physiotherapy and Rehabilitation, Balıkesir, Turkey \\ ${ }^{3}$ Kırıkkale University, Faculty of Medicine, Department of Physical Medicine and Rehabilitation, Kırıkkale, Turkey
}

Cite this article as: Aydoğan Arslan S, Uğurlu K, Savcun Demirci C, Keskin ED. Investigating the relation between upper extremity function and trunk control, balance and functional mobility in individuals with stroke. J Health Sci Med 2021; 4(2): 127-131.

\begin{abstract}
Aim: The purpose of our study was to examine the relation between upper extremity function and trunk control, balance and functional mobility and to compare trunk control, balance, and mobility with respect to upper extremity motor function level in individuals with stroke.

Material and Method: This study included a total of 39 stroke patients (age 63.87 \pm 9.03 years, post stroke $19.18 \pm 16.38$ month). Upper extremity motor functions were evaluated with the upper extremity sub-scale of the Stroke Rehabilitation Assessment of Movement (STREAM) Scale and Brunnstrom stages of motor recovery; trunk control, balance, and functional mobility were evaluated with Trunk Impairment Scale (TIS), Berg Balance Scale (BBS), and Timed Up and Go Test (TUG) respectively.

Result: A moderate relation was determined between the trunk control, balance and functional mobility and upper extremity functions $(\mathrm{p}<0.05)$. When the trunk control, balance and mobility performances of the individuals were compared according to Brunnstrom arm stages, it was seen that those with worse upper extremity motor recovery had poor trunk control, balance and mobility $(\mathrm{p}<0.05)$

Conclusion: As a result of our study, a relation was detected between upper extremity function and trunk control, balance and mobility. For this reason, it is important to focus on the upper extremity as well as trunk control to improve balance and mobility in physiotherapy and rehabilitation practices.
\end{abstract}

Keywords: Stroke, postural balance, upper extremity function

\section{INTRODUCTION}

Stroke is a central nervous system disease that has a great impact on public health as the cause of long-term disability. Upper Extremity dysfunction, which occurs after stroke, is one of the most common motor problems. Upper extremity problems greatly affect functional disability in approximately $80 \%$ of the patients (1). Many studies in the literature reported the importance of upper extremity disorder in people and the extent to which this affects the quality of performance in daily work activities $(2,3)$.

As well as upper extremity problems, another important problem in individuals with stroke is the use of atypical body characterized by weakness and abnormal compensatory strategies. Trunk plays important roles as a central axis in stabilizing the proximal movements for functional movements of the extremities and smooth performance of distal movements. For this reason, trunk stability is important for motor performance, postural balance, and coordinated extremity use in daily functional activities in recovery process (4-6). For this reason, it is very important to acquire trunk control at an early stage in the rehabilitation process (7).

When the literature was reviewed, many studies $(8,9)$ evaluating trunk control, balance, and lower extremity motor functions were detected; however, fewer studies were seen examining the effect of upper extremity functions on postural control and balance (10). As a matter of fact, decreased arm oscillations as a result of upper extremity problems affect postural balance negatively, and increase the risk of falls (11). Hyndman et al. (12) conducted a study, and reported worse upper extremity functions of 
individuals with a history of fall when they compared individuals with fall history and individuals without a history of fall. Arm movements help keep the center of gravity within the support surface during walking (13).

For this reason, it is very important to evaluate the upper extremity functions with trunk control and balance for the planning of an effective rehabilitation program in individuals with stroke. In addition, no study comparing trunk control and balance in stroke individuals with different upper extremity motor levels has been found in the literature. The purpose of our study was to examine the relation between upper extremity motor function and trunk control, balance and functional mobility in individuals with stroke and to compare trunk control, balance, and mobility with respect to upper extremity motor function level.

\section{MATERIAL AND METHOD}

\section{Participants and Design}

The study was conducted between January 2020 and November 2020. Individuals between the ages of 18-75 years who applied to Physiotherapy and Rehabilitation clinic of Kurlkkale University Faculty of Medicine, diagnosed with ischemic or hemorrhagic stroke, who had no communication problems and who could walk independently with or without an assistive device were included.

Aside from stroke, patients who had another brain tumor, multiple sclerosis, etc. neurological disease, or orthopedic problem, cardiopulmonary disease, agnosia or visual impairment, cooperative and communication problems that would affect functionality, balance, and upper extremity use were not included in the study. The study was approved by Non-Interventional Ethics Committee of University of Kirıkkale (decision no: 2019.11.09; date: 18.12.2019). Informed consent forms were obtained from all participating individuals.

\section{Data Collection Tools}

The socio-demographic characteristics of all individuals (age, height, body weight, body mass index, exercise and smoking habits, dominant side, lesion side, stroke type and onset, comorbid states, etc.) were recorded in the scope of the study. Upper extremity functions were evaluated with the upper extremity sub-scale of the Stroke Rehabilitation Assessment of Movement (STREAM) instrument; trunk control, balance, and functional mobility were evaluated with Trunk Impairment Scale (TIS), Berg Balance Scale (BBS), and Timed Up and Go Test (TUG) respectively. The upper extremity motor recovery level of the patients was clinically evaluated with the Brunnstrom stages of recovery.

\section{Stroke Rehabilitation Assessment of Movement}

It is used for clinical motor evaluation in stroke patients. The scale consists of a total of 3 parts as Upper Extremity (UE) voluntary act, lower extremity involuntary act, and basic mobility. Each part consists of 10 items, and is scored separately. The extremity movements are scored between 0 and 2 in a 3-point scale. The total score in STREAM UE is between 0 and 20. The scores are given according to the quality of the movement and the amount of doing it (14).

\section{Trunk Impairment Scale}

It was developed to evaluate the trunk balance (control) in patients who had neurological impairments. TIS consists of 17 parameters evaluating static ( 3 parameters, 7 points in total), and dynamic (10 parameters, 10 points in total) sitting balance, and trunk coordination (4 parameters, 6 points in total). TIS items are scored over 2 and 3 scores. The total score is $0-23$. Higher scores indicate better performance $(15,16)$.

\section{Berg Balance Scale}

It was designed to evaluate the static and dynamic balance, and identify the risk of falls. BBS consists of 14 items aimed to observe the protection of trunk balance during performance directly. Each item is scored between 0 and 4 . The test measures the level of dependency and/or independency during positions like standing without sitting, standing with feet adjacent, standing in tandem position, balance on one leg, and the ability of the person to make position changes. According to the scores obtained from this test, individuals are divided into "high risk of falling (0-20 points)", "medium risk of falling (21-40 points)", "low risk of falling (41-56 points)", and the highest score of 56 is considered to show the best balance (17).

\section{Timed Up and Go Test}

It is applied to evaluate the risk of functional mobility and fall of patients. A standard chair is used for this test. Firstly, the patient is asked to sit on the chair. Then, the individual is asked to stand up from the chair, walk regularly at a distance of predetermined 3 meters, return at the end of 3 meters, and sit in the chair again. In the test, the patient's walking time is recorded in seconds with a stopwatch. The test is repeated 3 times, and the mean value is recorded (18).

\section{Brunnstrom stages of motor recovery}

Brunnstrom motor recovery evaluation consists of 6 stages. Higher Brunnstrom stages indicate better motor recovery (19).

\section{Statistical Analysis}

The SPSS 21.0 (SPSS Inc., Chicago, Illinois, USA) program was used for the analysis of the data. The agreement of the variables to normal distribution was checked with Shapiro-Wilk Test. The homogeneity of the group variables was checked with the Levine Test. $\mathrm{P}<0.05$ level was considered to be statistically significant. 
The descriptive statistics were given as mean \pm standard deviation (mean $\pm \mathrm{SD}$ ). The Spearman Correlation Test was used in the relation measurements between the variables. Correlation coefficients were interpreted as $0-0.19=$ very low, $0.20-0.39=$ low, $0.40-0.69=$ moderate, $0.70-0.89=$ high, $0.90-1.0=$ very high correlation (20). The post-hoc power analysis with $\mathrm{G}^{\star}$ Power program (version 3.0.10 Universität Düsseldorf, Düsseldorf, Germany) was also used. In the post-hoc power analysis, when the statistical significance of alpha was found to be $5 \%$, and the confidence interval was taken as $95 \%$, the power $(1-\beta)$ of the study was found to be $96 \%$. The primary outcome was determined as TIS and STREAM upper extremity score. Effect size was calculated as 0.524 .

\section{RESULTS}

This study included a total of 39 stroke patients (age $63.87 \pm 9.03$ years, post stroke $19.18 \pm 16.38$ month). The sociodemographic and clinical data of the individuals are given in Table 1.

\begin{tabular}{|c|c|}
\hline & Participants \\
\hline \multicolumn{2}{|l|}{ Gender } \\
\hline Female, n (\%) & $11(28.2)$ \\
\hline Male, n (\%) & $28(71.8)$ \\
\hline Age, (years) median (minimum-maximum) & $64(41-81)$ \\
\hline BMI, $\left(\mathrm{kg} / \mathrm{m}^{2}\right)$ median (minimum-maximum) & $26.57(20.20-36.33)$ \\
\hline $\begin{array}{l}\text { Stroke duration (month) median (minimum- } \\
\text { maximum) }\end{array}$ & $12(1-48)$ \\
\hline \multicolumn{2}{|l|}{ Brunnstrom stage-arm, n (\%) } \\
\hline Brunnstrom-arm $\leq 3$ & $20(51.3)$ \\
\hline Brunnstrom-arm $>3$ & $19(48.7)$ \\
\hline \multicolumn{2}{|l|}{ Stroke type, n (\%) } \\
\hline Hemorrhagic & $11(28.2)$ \\
\hline Ischemic & $28(71.8)$ \\
\hline \multicolumn{2}{|l|}{ Dominant side, $\mathrm{n}(\%)$} \\
\hline Right & $35(89.7)$ \\
\hline Left & $4(10.3)$ \\
\hline \multicolumn{2}{|l|}{ Affected side n (\%) } \\
\hline Right & $14(35.9)$ \\
\hline Left & $25(64.1)$ \\
\hline \multicolumn{2}{|l|}{ Falling history $\mathrm{n}(\%)$} \\
\hline Nonfaller & $28(71.3)$ \\
\hline Faller & $11(28.2)$ \\
\hline $\begin{array}{l}\text { Stream upper extremity score, median } \\
\text { (minimum-maximum) }\end{array}$ & $7(0-20)$ \\
\hline BBS score, median (minimum-maximum) & $46(7-56)$ \\
\hline $\begin{array}{l}\text { TUG (second), median (minimum- } \\
\text { maximum) }\end{array}$ & $19(6.01-90)$ \\
\hline TIS score, median (minimum-maximum) & $14(3-23)$ \\
\hline \multicolumn{2}{|c|}{$\begin{array}{l}\text { BMI: Body mass index; STREAM: The stroke rehabilitation assessment of movement } \\
\text { scale. BBS: Berg balance scale; TUG: Timed up and go test; TIS: Trunk impairment } \\
\text { scale }\end{array}$} \\
\hline
\end{tabular}

A moderate relation was determined between the trunk control, balance and functional mobility and upper extremity functions $(\mathrm{p}<0.05$, Table 2$)$.

When the trunk control, balance and mobility performances of the individuals were compared according to Brunnstrom arm stages, it was seen that those with worse upper extremity motor recovery had poor trunk control, balance and mobility $(\mathrm{p}<0.05$, Table 3$)$.

\begin{tabular}{|c|c|c|c|c|c|}
\hline & Stream-UE & TIS & BBS & TUG & \\
\hline Stream-UE & - & - & - & - & - \\
\hline TIS & $\begin{array}{l}r=0.803^{*} \\
p=0.001\end{array}$ & - & - & - & - \\
\hline BBS & $\begin{array}{l}r=0.524^{\star} \\
\mathrm{p}=0.001\end{array}$ & $\begin{array}{l}r=0.672^{*} \\
p=0.001\end{array}$ & - & - & - \\
\hline TUG & $\begin{array}{l}r=0.394^{*} \\
p=0.013\end{array}$ & $\begin{array}{l}r=0.499^{*} \\
\mathrm{p}=0.001\end{array}$ & $\begin{array}{c}r=-0.809^{*} \\
p=0.001\end{array}$ & - & - \\
\hline $\begin{array}{l}{ }^{*} \mathrm{p}<0.05 \text {; STREA } \\
\text { Upper Extremity } \\
\text { Up and Go Test }\end{array}$ & $\begin{array}{l}\text { M-UE: The Strok } \\
\text { TIS: Trunk Impa }\end{array}$ & $\begin{array}{l}\text { Rehabilitatic } \\
\text { ment Scale; B }\end{array}$ & $\begin{array}{l}\text { n Assessment } \\
\text { BS: Berg Balanc }\end{array}$ & Mover & $\begin{array}{l}\text { icale- } \\
\text { imed }\end{array}$ \\
\hline
\end{tabular}

Table 3. Comparison of upper extremity motor functions, balance, trunk control and functional mobility according to the level of Brunnstrom stages in stroke individuals

\begin{tabular}{|lccc|}
\hline & $\begin{array}{c}\text { Brunnstrom-arm } \leq 3 \\
(\mathbf{n}=\mathbf{2 0})\end{array}$ & $\begin{array}{c}\text { Brunnstrom-arm }>3 \\
(\mathbf{n = 1 9 )}\end{array}$ & $\begin{array}{c}\mathbf{p} \\
\text { value }\end{array}$ \\
\hline Stream-UE & $4.78 \pm 3.90$ & $13.15 \pm 6.34$ & 0.001 \\
TIS & $10.90 \pm 4.17$ & $16.94 \pm 4.46$ & 0.001 \\
BBS & $34.25 \pm 15.45$ & $45.31 \pm 10.72$ & 0.007 \\
TUG & $41.35 \pm 29.09$ & $19.90 \pm 15.69$ & 0.011 \\
\hline $\begin{array}{l}\text { *p<0.05; STREAM-UE: The Stroke Rehabilitation Assessment of Movement Scale- } \\
\text { Upper Extremity; TIS: Trunk Impairment Scale; BBS: Berg Balance Scale; TUG: Timed } \\
\text { Up and Go Test }\end{array}$ & \multicolumn{4}{l}{} \\
\hline
\end{tabular}

\section{DISCUSSION}

As a result of our study, it was found that there is a relation between upper extremity functions and trunk control, balance, and mobility; and it was seen that patients with worse upper extremity functions had more disrupted trunk control, balance and mobility. Accordingly that upper extremity motor dysfunction as well as trunk control may be a factor adversely affecting the balance and mobility in individuals with stroke. When the literature was examined, the effect of lower extremity functions on mobility and balance was investigated (21), or the relations between upper extremity functions and trunk control, and the effects of trunk control on upper extremity performance were examined in current studies (22). The focus was also on the effect of shoulder sling or orthosis use on trunk control or on balance and gait in patients with upper extremity affected, or the effect of rehabilitation programs on upper extremity functions (23-26). 
Wee et al. (27) investigated the relations between the restoration of upper extremity functions in the lower extremity function in stroke patients, and reported that the external trunk support in the lower extremity function had a significant effect on the upper extremity function. It was also reported that the recovery of upper extremity function developed in connection with the improvement of the trunk functions, and the trunk was decisive in the recovery of the upper extremity functions of the trunk in stroke patients.

For this reason, in our study, the effects of primarily upper extremity motor functions, but also trunk control, on balance and mobility in individuals with stroke were investigated.

The trunk is the most important dynamic stabilizer of the trunk, and is also the most important part of hemiplegia rehabilitation. The trunk muscles, which are active during sitting and standing, being affected after a stroke causes hemiplegic patients to experience activity limits (28).

Upper extremity function and posture are interconnected systems and are necessary to gain trunk control and improve the quality of upper extremity movements. In this sense, the development of postural control increases the function of upper extremities; and upper extremity movements are also important for the development of postural control, facilitating the trunk muscles. Ustinova et al. (29) conducted a study to determine how arm movements affect postural oscillation in hemiplegia patients, and found that while the center of pressure arm movement slid reverse in oscillation stage in healthy individuals, center of pressure and arms moved in the same direction in hemiplegic individuals. In other words, during the posture phase in healthy individuals, the trunk balanced the arm movements, the trunk moved with the affected arm in hemiplegic patients. As a result of the study, researchers concluded that stroke caused abnormal patterns in the interaction of the arm-trunk and center of gravity. Similarly, in another study, it was reported that there were highly positive relations between upper extremity functions and postural control (30). Ashburn et al. (31) evaluated individuals with stroke for the risk of falling after discharge, and reported that there were higher risks of falling in individuals with upper extremity dysfunction. For this reason, strategies to minimize the risk of falling in stroke individuals should also be given importance among the planned treatment approaches to improve upper extremity functions.

Actually, this is a vicious circle. Problems in both affect each other negatively. Based on these studies, although it is known how much trunk control affects the functional use of the upper extremity, the severity of upper extremity involvement is also important for trunk control, balance and mobility. In our study, when we compared the trunk control and balance levels of individuals with stroke according to the upper extremity Brunnstrom recovery stages, we found that individuals with better upper extremity functions had better balance and mobility of trunk control. For this reason, approaches to improve upper extremity functions should be considered among the treatment strategies planned in individuals with stroke. We believe that our study results can bring a different perspective to researchers.

\section{Limitation}

The limitation of our study was that the upper extremity functions are only considered with STREAM, there was no control group, and the affected side is not taken into account. STREAM evaluates only the quality of the movement. Fine and gross motor skills and functionality should also be evaluated in terms of upper extremity functions. Also, considering that the affected part may affect postural control, we recommend that these should be evaluated in future studies in detail.

\section{CONCLUSION}

As a result of our study, it was concluded that there is a relationship between upper extremity function and trunk control and balance and functional mobility, and those with poorer upper extremity functions and trunk control have worse balance. When we compared the trunk control, balance levels and mobility of individuals with stroke according to the upper extremity brunnstrom recovery stages, we found that individuals with better upper extremity functions had better balance, mobility and trunk control. Therefore, in physiotherapy and rehabilitation applications, it is important to focus on the upper extremity as well as trunk control to improve postural control, balance and mobility.

\section{ETHICAL DECLARATIONS}

Ethics Committee Approval: The study was approved by Non-Interventional Ethics Committee of University of Kurkkkale (decision no: 2019.11.09; date: 18.12.2019). Informed consent forms were obtained from all participating individuals.

Informed Consent: Written informed consent was obtained from all participants who participated in this study.

Conflict of Interest Statement: The authors have no conflicts of interest to declare.

Financial Disclosure: This research received no specific grant from any funding agency in the public, commercial, or not-for-profit sectors. 
Author Contributions: All of the authors declare that they have all participated in the design, execution, and analysis of the paper, and that they have approved the final version.

Acknowledgments: The authors would like to express their gratitude to all the participants of the study.

\section{REFERENCES}

1. Langhorne P, Bernhardt J, Kwakkel G. Stroke rehabilitation. Lancet 2011; 377: 1693-702.

2. Charlotte Brunner I, Sture Skouen J, Inger Strand L. Recovery of upper extremity motor function post stroke with regard to eligibility for constraint-induced movement therapy. Top Stroke Rehabil 2011; 18: 248-57.

3. Likhi M, Jidesh V, Kanagaraj R, George JK. Does trunk, arm, or leg control correlate best with overall function in stroke subjects? Top Stroke Rehabil 2013; 20: 62-7.

4. Isho $\mathrm{T}$, Usuda S. Association of trunk control with mobility performance and accelerometry-based gait characteristics in hemiparetic patients with subacute stroke. Gait Posture 2016; 44: 89-93.

5. Duarte E, Marco E, Muniesa JM, Belmonte R, Aguilar JJ, Escalada F. Early detection of non-ambulatory survivors six months after stroke. Neuro Rehabilitation 2010; 26: 317-23.

6. Ryerson S, Byl NN, Brown DA, Wong RA, Hidler JM. Altered trunk position sense and its relation to balance functions in people post-stroke. J Neurol Phys Ther 2008; 32: 14-20.

7. Hsieh C-L, Sheu C-F, Hsueh I-P, Wang C-H. Trunk control as an early predictor of comprehensive activities of daily living function in stroke patients. Stroke 2002; 33: 2626-30.

8. Carozzo S, Serra S, Pignolo L, Tonin P, Cerasa A. The assessment of trunk recovery in stroke patients using $3 \mathrm{D}$ kinematic measures. Med Eng Phys 2020; 78: 98-105.

9. Karthikbabu S, Verheyden G. Relationship between trunk control, core muscle strength and balance confidence in communitydwelling patients with chronic stroke. Top Stroke Rehabil 2020: 1-8.

10. Rafsten L, Meirelles C, Danielsson A, Stibrant Sunnerhagen K. Impaired motor function in the affected arm predicts impaired postural balance after stroke: a cross sectional study. Front Neurol 2019; 10: 912 .

11. Chou CH, Hwang YS, Chen CC, Chen SC, Lai CH, Chen YL. FES for abnormal movement of upper limb during walking in poststroke subjects. Technol Health Care 2014; 22: 751-8.

12.Hyndman D, Ashburn A, Stack E. Fall events among people with stroke living in the community: circumstances of falls and characteristics of fallers. Arch Phys Med Rehabil 2002; 83: 165-70.

13. Pijnappels M, Kingma I, Wezenberg D, Reurink G, Van Dieën JH. Armed against falls: the contribution of arm movements to balance recovery after tripping. Exp Brain Res 2010; 201: 689-99.

14. Hsueh IP, Wang WC, Wang $\mathrm{CH}$, et al. A simplified stroke rehabilitation assessment of movement instrument. Phys Ther 2006; 86: 936-43.

15. Verheyden G, Vereeck L, Truijen S, et al. Trunk performance after stroke and the relationship with balance, gait and functional ability. Clin Rehabil 2006; 20: 451-8.

16. Sag S, Buyukavci R, Sahin F, Sag MS, Dogu B, Kuran B. Assessing the validity and reliability of the Turkish version of the Trunk Impairment Scale in stroke patients. North Clin Istanb 2019; 6: 156.

17.Şahin F, Büyükavci R, Sağ S, Doğu B, Kuran B. Reliability and validity of the Turkish version of the berg balance scale in patients with stroke. Turk J Phys Med Rehab 2013; 16.
18. Hill KD, Bernhardt J, McGann AM, Maltese D, Berkovits D. A new test of dynamic standing balance for stroke patients: reliability, validity and comparison with healthy elderly. Physiother Can 1996; 48: 257-62.

19. Brunnstrom S. Motor testing procedures in hemiplegia: based on sequential recovery stages. Phys Ther 1966; 46: 357-75.

20.Hayran M. Sağlık araştırmaları için temel istatistik: Omega Araştırma; 2011.

21.Hendrickson J, Patterson KK, Inness EL, Mcllroy WE, Mansfield A. Relationship between asymmetry of quiet standing balance control and walking post-stroke. Gait Posture 2014; 39: 177-81.

22. Wee SK, Hughes A-M, Warner M, Burridge JH. Trunk restraint to promote upper extremity recovery in stroke patients: a systematic review and meta-analysis. Neurorehabil Neural Repair 2014; 28 : 660-77.

23. Acar M, Karatas GK. The effect of arm sling on balance in patients with hemiplegia. Gait Posture 2010; 32: 641-4.

24. Aprile I, Germanotta M, Cruciani A, et al. Upper limb robotic rehabilitation after stroke: a multicenter, randomized clinical trial. J Neurol Phys Ther 2020; 44: 3-14.

25. Kim J-O, Lee B-H. Effect of upper extremity coordination exercise during standing on the paretic side on balance, gait ability and activities of daily living in persons with stroke. J Phys Ther Sci 2017; 6: 53-8.

26. Peters HT, Page SJ, Persch A. Giving them a hand: wearing a myoelectric elbow-wrist-hand orthosis reduces upper extremity impairment in chronic stroke. Arch Phys Med Rehabil 2017; 98: 1821-7.

27. Wee, SK. Relationship between trunk control and recovery of upper extremity function in stroke patients. $\mathrm{PhD}$ Thesis. University of Southampton, 2015.

28. Karthikbabu S, Chakrapani M, Ganeshan S, Rakshith KC, Nafeez $\mathrm{S}$, Prem V. A review on assessment and treatment of the trunk in stroke: a need or luxury. Neural Regen Res 2012; 7: 1974.

29. Ustinova KI, Goussev VM, Balasubramaniam R, Levin MF. Disruption of coordination between arm, trunk, and center of pressure displacement in patients with hemiparesis. Motor Control 2004; 8: 139-59.

30. Geler Külcü D, Yanık B, Gülșen G. The relationship between balance disorders and upper extremity function in hemiplegic patients. J PMR Sci 2009; 12: 1-6.

31. Ashburn A, Hyndman D, Pickering R, Yardley L, Harris S. Predicting people with stroke at risk of falls. Age Ageing 2008; 37: 270-6. 